\title{
An easy-to-use colorimetric enzymatic test-system for organophosphorus insecticides detection in olive oil
}

\author{
Najwa Ben Oujji ${ }^{1,2}$, Idriss Bakas ${ }^{1,2}$, Georges Istamboulie ${ }^{1}$, Ihya Ait-Ichou ${ }^{2}$, Elhabib Ait-Addi ${ }^{2}$, \\ Régis Rouillon ${ }^{1}$, Thierry Noguer ${ }^{1}$ \\ ${ }^{1}$ University of Perpignan, IMAGES EA4218, 52 Av. Paul Alduy, 66860 Perpignan Cedex, France \\ ${ }^{2}$ University Ibn Zohr, Photocatalysis and Environment Team, Chemistry Department/Faculty of Science, Agadir, Morocco
}

\section{Email address:}

najwa_benoujji@hotmail.com (N. Ben oujji), najwabenoujji@gmail.com (N. Ben oujji)

\section{To cite this article:}

Najwa Ben Oujji, Idriss Bakas, Georges Istamboulie, Ihya Ait-Ichou, Elhabib Ait-Addi, Régis Rouillon, Thierry Noguer. An Easy-to-Use Colorimetric Enzymatic Test-System for Organophosphorus Insecticides Detection in Olive Oil. Science Innovation. Special Issue: Biosensors: Innovative Technique for Food Safety and Environmental Monitoring. Vol. 2, No. 6-1, 2014, pp. 5-9. doi: 10.11648/j.si.s.2014020601.12

\begin{abstract}
Immobilization of a low amount of electric eel acetylcholinesterase on microtiter plates by bioencapsulation in a sol-gel composite led to the preparation of a simple colorimetric enzymatic-assay for pesticides detection in olive oil. This bioassay has been used to carry out inhibition studies with three pesticides mainly used in the treatment of olive trees: Malaoxon, Methidathion-oxon and Omethoate, and tested using standard solutions and real samples of olive oil. The developed bio-tools showed a good reproducibility and stability as well as good analytical performances with limits of detection at least 10 times less than the maximum residue limit tolerated by international regulations. The obtained LODs were as low as $10^{-9} \mathrm{M}$ for the widely used pesticide Malaoxon, $10^{-8} \mathrm{M}$ for Methidathion oxon and $10^{-7} \mathrm{M}$ for Omethoate. The developed test was designed for fast detection of the three target insecticides in such a complex matrix as olive oil without a laborious pre-treatment and after a simple liquid-liquid extraction, which demonstrate the potentiality of this technique to be used for commercial purpose.
\end{abstract}

Keywords: Electric Eel Acetylcholinesterase, Bioassays, Organophosphorus Insecticides, Olive Oil, Colorimetric Test, Sol-Gel

\section{Introduction}

The cultivation of olive trees to obtain olives and olive oil has been known since antiquity. At the time of the Roman Empire, olive cultivation had spread throughout the Mediterranean basin and today, with $98 \%$ of olive trees that exist in the world, the Mediterranean countries present the big part of the world production of this yield. Olive oil is the main ingredient and essential component of the healthy diet for majority of people living in that area, since it possesses highly beneficial nutritional and culinary properties due to its unique composition in containing fatty acids and antioxidants [1]. Considering these beneficial properties and increasing worldwide distribution, there has been an extended demand for efficient cultivation and mass production of olive oil [2]. Beside relevant advances in production, there are some serious problems caused by different insects which attack and damage olive trees. One of them is the common olive oil fruit fly Bactrocera oleae, which induces an increase of acidity, affects fruits shelf life and decreases the yield of the olives. In order to protect trees from the infection and avoid significant losses in olive oil production, trees are usually treated with suitable pesticides which act as repellents against flies or other insects. Despite the advantages which agrochemicals offer for the improvement of the olive's yield, they still remain highly toxic and compromise the quality of olive oil. Therefore, regular monitoring and detection of these chemicals are essential for consumer protection and healthy diet [3].

Pesticide-residue determination in olive oil is becoming a very important and challenging issue. Conventional methods of detection of organophosphorus pesticides rely on an analysis by gas chromatography with specific detection. Although these techniques are very powerful and can detect very low concentrations, they are still very expensive and require highly skilled personnel, expensive purification steps and specialized major equipment. In the last decades, new technologies based on biological detection systems have emerged. Among these techniques, biosensors have been shown to be very promising due to their simplicity and cost effectiveness compared to conventional techniques [4]. 
Biosensors and bioassays based on the inhibition of acetylcholinesterase (AChE) and other enzymes have been intensively studied in the aim of detecting organophosphorus insecticides in water and other matrix, but in our knowledge, it's the first time a study have interested to the development of enzymatic tools to detect these compound in olive oil.

The present paper describes the development of a Simple Colorimetric Enzymatic-Assay for the rapid and sensitive detection of three organophosphorus insecticides widely used in the treatment of olive trees: Malaoxon, Omethoate and Methidathion-oxon. The systems are based on the immobilization of a low amount of electric eel acetylcholinesterase by bioencapsulation in a sol gel matrix on Elisa microplates. This test presents the advantage of saving time, reagents and solvents as it allows analyzing 96 samples in a single assay in just $2 \mathrm{~h}$, this time including the samples preparation, the incubation with pesticides and the enzymatic measurement, using small volumes of chemicals reagents and solvents, which is not possible using the traditional chromatographic systems.

\section{Materials and Methods}

\subsection{Chemicals and Stock Solutions}

AChE (EC 3.1.1.7) from electric eel (EE) (Type V-S, 1,000 $\mathrm{U} / \mathrm{mg}$ ) was purchased from Sigma-Aldrich (St Quentin-Fallavier, France). Acetylthiocholine Iodide (ATChI), and 5,5-dithiobis(2-nitrobenzoic acid) (DTNB-Ellman's reagent) were provided by Sigma. In order to minimize hydrolysis, ATChI solution was prepared daily in $0.9 \% \mathrm{NaCl}$ (Sigma-Aldrich) solution. Stock solutions of enzymes and DTNB were prepared in $0.1 \mathrm{M}$ phosphate buffer $\left(\mathrm{Na}_{2} \mathrm{HPO}_{4} / \mathrm{KH}_{2} \mathrm{PO}_{4}\right.$, Sigma-Aldrich) at $\mathrm{pH}$ 7. The organophosphorus insecticides Malaoxon, Omethoate and Methidathion were purchased from Dr. Ehrenstorfer (Augsburg, Germany). Pesticide stock solutions (concentration $10^{-3} \mathrm{M}$ ) were prepared in acetonitrile and stored at $4{ }^{\circ} \mathrm{C}$, working pesticide solutions were prepared daily in distilled water by dilution of the stock solution. The oxidation of Methidathion was achieved using N-bromosuccinimide (NBS) provided by Sigma-Aldrich. Hexane, Acetonitrile and Dichloromethane were purchased from Sigma-Aldrich (France). Sol-gel matrices were prepared using tetramethoxysilane (TMOS), poly(ethyleneglycol) 600 (PEG), hydroxyethyl-cellulose (HEC) (Sigma-Aldrich) and hydrochloric acid $(\mathrm{HCl})$ from Carlo Erba, Italy.

\subsection{Apparatus}

The determination of AChE activity was carried out with a Hewlett Packard diode array 8451A spectrophotometer. Colorimetric measurements were performed with a Labsystems Multiskan EX 126 microtiter plate reader (Thermo Life Sciences, Cergy Pontoise, France). The enzyme was immobilized on microtiter plates PS, form U, 96 wells (Greiner, Germany) and Chromatographic measurements were performed using an HPLC L-2000 series LaChrom
Elite ${ }^{\circledR}$ system from Merck-Hitachi (VWR, France).

\subsection{Determination of Acetylcholinesterase Activity}

The activity of AChE was measured spectrophotometrically by monitoring at $412 \mathrm{~nm}$ the appearance of thionitrobenzoate resulting from the reaction of DTNB with thiocholine, the product of the enzymatic hydrolysis of acetylthiocholine substrate, according to the procedure described by Ellman et al. [5]. This method is based on the use of a synthetic substrate: acetylthiocholine, whose hydrolysis liberates thiocholine and acetic acid according to the reaction:

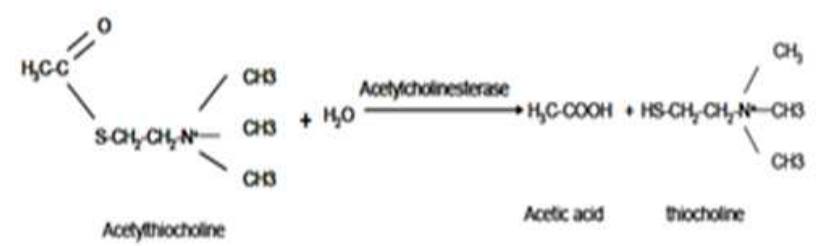

The thiocholine reacts with 5,5'-dithiobis-(2-nitrobenzoic acid) (DTNB) yielding a yellow complex absorbing at $412 \mathrm{~nm}$ $\left(\varepsilon=1.36 \times 10^{4} \mathrm{M}^{-1} \mathrm{~cm}^{-1}\right)($ Figure 1$)$

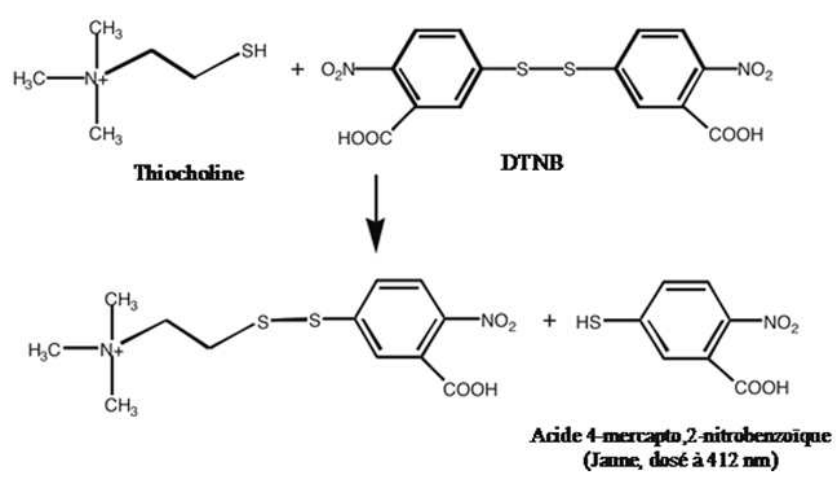

Figure 1. Colorimetric Detection of thiocholine by Ellman method (1961)

\subsection{Immobilization Protocol}

The Immobilization of the bioreceptor presents the first and the most important step in the development of a bioassay. It can be defined as a technique which limits the free displacement of the biological element. The immobilization method used must retain maximum enzyme activity and preserve the three-dimensional conformation of the enzyme, especially at its active site. In this study, the research has been directed towards the sol-gel technique to attach the enzyme to the microplate:

The sol-gel technique has been known for over than 150 years thanks to Ebelmen, which was the first to describe the synthesis of silica from a silicon alkoxide [6]. Recently, this process has been used to entrap a wide variety of biological species, including enzymes and living microorganisms for various applications $[7 ; 8]$.

Sol-gel process involves hydrolysis of alkoxide precursors under acidic conditions followed by condensation of the hydroxylated units, which leads to the formation of a porous gel. First, a low-molecular weight metal alkoxide precursor molecule such as tetramethoxysilane (TMOS) or 
tetraethoxysilane (TEOS) is hydrolysed in the presence of water at acidic $\mathrm{pH}$, resulting in the formation of $(\mathrm{Si}-\mathrm{OH})$ groups. In a second step, the condensation reaction between silanol moieties at alkaline $\mathrm{pH}$ results in the formation of siloxane ( $\mathrm{Si}-\mathrm{O}-\mathrm{Si})$ polymers, creating a matrix in which an enzyme can be successfully entrapped [9]. In some cases, the cracking of the sol-gel polymers can be prevented using doping agents such as poly(ethyleneglycol).

In this work the protocol of immobilization was the following: the sol-gel solution was prepared by mixing $150 \mu \mathrm{L}$ of the precursor tetramethoxysilane (TMOS) with $413 \mu \mathrm{L}$ of distilled water, $400 \mu \mathrm{L}$ of $\mathrm{HCl} 1 \mathrm{mM}$, and $37 \mu \mathrm{L}$ of PEG 600 . This mixture was sonicated for $15 \mathrm{~min}$ and stored for one night at $4{ }^{\circ} \mathrm{C}$. The enzymatic solution prepared in phosphate buffer $(\mathrm{pH})$ was mixed $1: 1(\mathrm{v} / \mathrm{v})$ with HEC $(2 \%)$. Then, this solution was mixed with the sol-gel in a ratio $2: 1(\mathrm{v} / \mathrm{v})[10] .20$ $15 \%$ TMOS et $40 \% \mathrm{HC}$

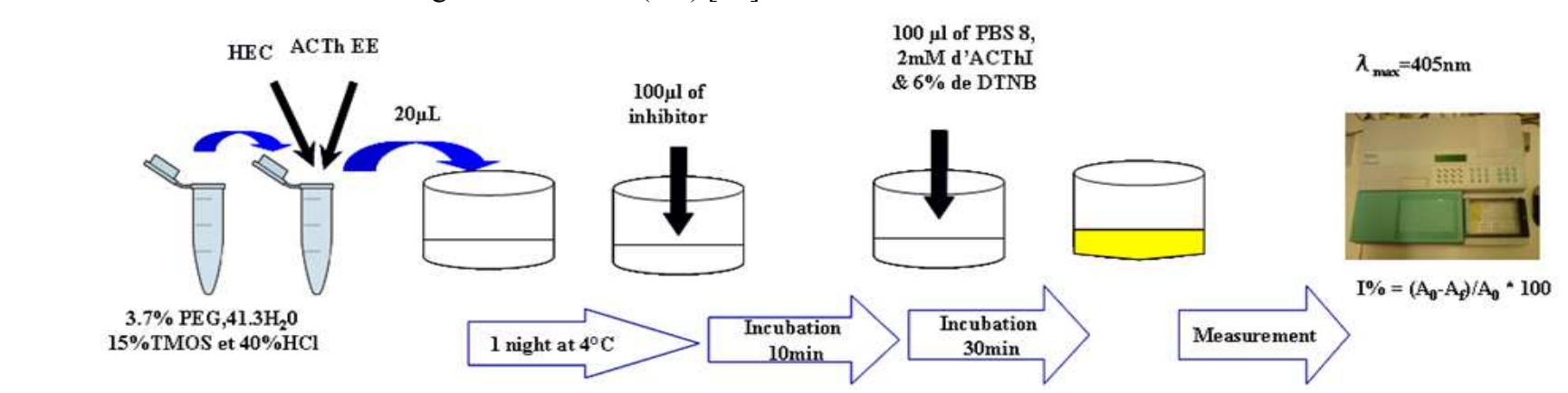

$\mu \mathrm{L}$ of the obtained solution was quickly spread at the bottom of the microtiter plate wells and allowed to dry for one night at $4{ }^{\circ} \mathrm{C}$, so the final concentration of the enzyme immobilized in each well was $29 \mathrm{mIU}$.

\subsection{Colorimetric Measurements}

To measure the enzymatic activity of the fixed enzyme, 200 $\mu \mathrm{L}$ of phosphate buffer $\mathrm{pH} 8$ containing $2 \mathrm{mM}$ ACTh-I and $6 \%$ DTNB were added to the well, and the microplate was incubated for $30 \mathrm{~min}$ in room temperature. The absorbance was then measured at $405 \mathrm{~nm}$ using the Labsystems Multiskan EX 126 microtiter plate reader. The inhibition measurements were carried out using the same procedure as described above, after incubation of the immobilized enzyme for $10 \mathrm{~min}$ with $100 \mu \mathrm{L}$ of different concentrations of pesticide as shown in Figure 2.

Figure 2. Immobilization and colorimetric measurement protocols.

\subsection{Sample Preparation and Pesticides Extraction}

Many of the commercially available organophosphorus (OP) insecticides are phosphorothionates (lipophilic), which are characterized by one thione moiety $(\mathrm{P}=\mathrm{S})$ and three -OR groups attached to a phosphorus atom, whereas their respective oxidized analogues are more polar, characterized by a double phosphorus oxygen bond $(\mathrm{P}=\mathrm{O})$, which actually makes them less stable, more toxic and potent AChE inhibitors [11]. Therefore, this study focuses on the detection of the oxidized forms of three organophosphorus insecticides mainly used in the treatment of olive trees: Malathion, Dimethoate and Methidathion.

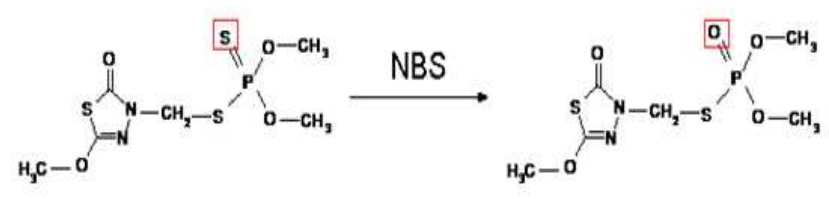

Figure 3. Oxidation of Methidathion using N-bromosuccinimide (NBS)

The oxidized forms of Dimethoate and Malathion, respectively called Omethoate and Malaoxon are commercially available, but in the case of methidathion an oxidation step must be carried out (Figure 3) using N-bromosuccinimide (NBS) [11]. The efficiency of this oxidation step was controlled using reverse-phase HPLC, it was shown that $3.10^{-5} \mathrm{M}$ NBS was sufficient for the total oxidation of a $10^{-5} \mathrm{M}$ Methidathion solution. The effect of NBS on AChE-EE has been also investigated to ensure that the enzyme was not affected by the oxidizing agent, it was shown that in assays conditions NBS did not inhibit AChE [12].

The determination of the three target pesticides in natural olive oil samples was performed after a simple liquid-liquid extraction procedure as described previously [12;13]: $10 \mathrm{~mL}$ of a commercially available bio extra virgin olive oil purchased in a local supermarket was spiked with a known concentration of pesticide diluted in Hexane. The mixture was heated at $50{ }^{\circ} \mathrm{C}$ for $30 \mathrm{~min}$, and $500 \mu \mathrm{L}$ of this olive oil was added to $400 \mu \mathrm{L}$ of acetonitrile and $100 \mu \mathrm{L}$ of dichloromethane. The mixture was centrifuged at 13,400 rpm for $90 \mathrm{~s}$ and the resulting supernatant was recovered and used as a pesticide mother solution, other pesticide solutions were prepared by diluting this mother solution.

\section{Results and Discussion}

\subsection{Reaction Time}

The incubation time required for the reaction between the immobilized enzyme and the substrate was evaluated by measuring the absorbance continuously for $35 \mathrm{~min}$ using the microtiter plate reader. It appears from the obtained kinetics, that the reaction was completed $30 \mathrm{~min}$ after the addition of the acetylthiocholine Iodide. This reaction time was therefore applied to all measurements.

\subsection{Storage Stability}

The storage stability of the developed devices was evaluated 
by measuring the enzymatic activity each day for two months. The results showed a good storage stability of the developed Kits, with less than $10 \%$ decrease of activity after one month of storage at $4{ }^{\circ} \mathrm{C}$ and $21 \%$ after 2 months (Figure 4 ).

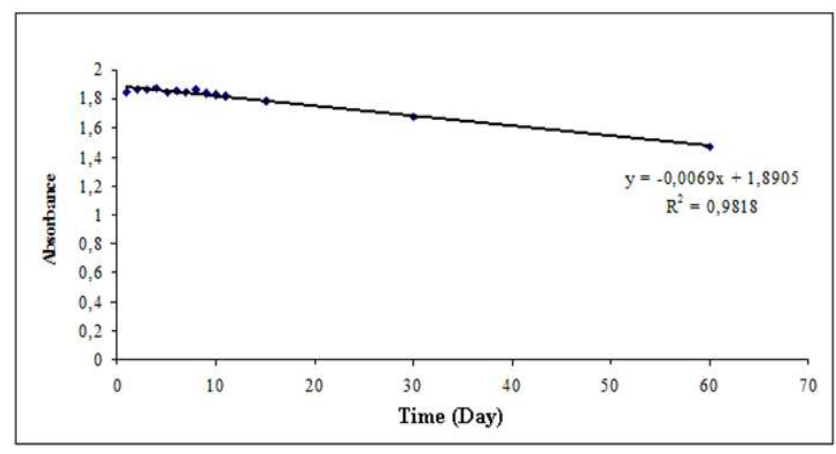

Figure 4. Storage stability of the developed Kits

The developed tests present also a good operational stability, as they maintained their initial analytical response for at least 7 successive determinations as well as a good reproducibility with a Relative Standard Deviation (RSD) of $3.4 \%$.

\subsection{Inhibition Measurements}

The insecticides detection was carried out using an incubation time between the enzyme and $100 \mu$ l of the inhibitor for $10 \mathrm{~min}$, the analytical performances of the developed colorimetric test for the detection of the three target pesticides are summarized in Table 1. The limit of detection LOD was defined as the pesticide concentration that produced $10 \%$ decrease of the signal $\left(\mathrm{IC}_{10}\right)$, whereas $\mathrm{IC}_{50}$ and $\mathrm{IC}_{100}$ are the concentrations of pesticides inducing respectively $50 \%$ and $100 \%$ decrease of the signal. It was found that the developed systems present good analytical performance with good limits of detection as low as $7 \times 10^{-9}$ for the Malaoxon, $3 \times 10^{-8}$ for the Methidathion oxon and $8 \times 10^{-8}$ for the Omethoate. The obtained LODs were at least 10 time less than the maximum residue limit tolerated by international regulations according to the French Ministry of Agriculture and Food in 2012 (AF920805) (see table 3)

Table 1. Performances of the developed bioassay for the detection of Omethoate, Methidathion-Oxon and Malaoxon. LOD (IC $\left.{ }_{10}\right)$, IC ${ }_{50}$ and $I C_{100}$ are the concentrations of pesticides inducing respectively $10 \%, 50 \%$ and $100 \%$ decrease of the signal.

\begin{tabular}{|c|c|c|c|c|c|c|}
\hline Pesticide & Equation & $\mathbf{R}^{2}$ & $\mathrm{IC}_{10}(\mathrm{M})$ & $\mathrm{IC}_{50}(\mathrm{M})$ & $\mathrm{IC}_{100}(\mathrm{M})$ & Dynamic Range (M) \\
\hline Omethoate & $\mathrm{I}=7.3113 \operatorname{Ln}(\mathrm{C})+129.24$ & 0.9894 & $8.2 \times 10^{-8}$ & $1.9 \times 10^{-5}$ & $1.2 \times 10^{-2}$ & $7.5 \times 10^{-8}-5 \times 10^{-3}$ \\
\hline Methidathion oxon & $\mathrm{I}=25.291 \mathrm{Ln}(\mathrm{C})+446.41$ & 0.9439 & $3.2 \times 10^{-8}$ & $1.5 \times 10^{-7}$ & $1.1 \times 10^{-6}$ & $7.5 \times 10^{-9}-10^{-6}$ \\
\hline Malaoxon & $\mathrm{I}=12.357 \operatorname{Ln}(\mathrm{C})+241.17$ & 0.9776 & $7.5 \times 10^{-9}$ & $1.9 \times 10^{-7}$ & $1.0 \times 10^{-5}$ & $5 \times 10^{-9}-7.5 \times 10^{-5}$ \\
\hline
\end{tabular}

\subsection{Real Samples Analysis}

Olive oil Samples were analysed before and after spiking with known concentrations of Malaoxon, Methidathion-oxon and Omethoate. The amount of pesticide spiked was $10^{-6} \mathrm{M}$, $7.5 \times 10^{-8} \mathrm{M}$ and $2.5 \times 10^{-7} \mathrm{M}$ for the Methidathion oxon; $2.5 \times 10^{-5}, 10^{-5}$ and $10^{-4} \mathrm{M}$ for the Omethoate and $10^{-8}, 5 \times 10^{-7}$ and $2.5 \times 10^{-7} \mathrm{M}$ for the Malaoxon. The unspiked samples revealed no inhibitory effect, whereas the results obtained with the spiked samples were consistent and in good agreement with the spiked amount of pesticides and present a good correlation with the inhibition rate obtained with standards solutions. Table 2 shows the recovery yields calculated as $\left(\% \mathrm{R}=\left(\mathrm{P}_{1} / \mathrm{P}_{0}\right) \times 100\right)$, where $\mathrm{P}_{0}$ is the added (real) quantity of pesticide and $\mathrm{P}_{1}$ is the found quantity.

Table 2. Recovery yields (\%) obtained for the determination of Omethoate, Malaoxon and Methidathion-Oxon pesticides in spiked olive oil samples. RSD $<3 \%$.

\begin{tabular}{lll}
\hline & Pesticide Concentration(M) & Recovery (\%) \\
\hline \multirow{3}{*}{ Omethoate } & $2.5 \times 10^{-5}$ & 102.32 \\
& $10^{-5}$ & 111.49 \\
& $10^{-4}$ & 114.70 \\
Methidathion Oxon & $10^{-6}$ & 117,14 \\
& $7.5 \times 10^{-8}$ & 108.37 \\
& $2.5 \times 10^{-7}$ & 109.96 \\
Malaoxon & $10^{-8}$ & 121.16 \\
& $5 \times 10^{-7}$ & 114.30 \\
& $2.5 \times 10^{-7}$ & 101.14 \\
\hline
\end{tabular}

A comparison between the limits of detection obtained by the developed test and the MRLs for these three pesticides according to the French Ministry of Agriculture and Food in 2012 (AF920805) is presented in Table 3. It should be noted that detection limits reported in this table are obtained by application of the devices on natural samples of olive oil. The obtained LODs are much lower than the maximum residue limit tolerated by international regulations.

Table 3. Comparison between the LODs obtained with the developed method and the LMRs establish by the French Department of Agriculture and Agrifood 2012 (AF920805) (ppm: parts-per-million).

\begin{tabular}{lll}
\hline & LMR (AF920805) & LOD \\
\hline Malaoxon & $0,5 \mathrm{ppm}$ & $0,001 \mathrm{ppm}$ \\
Methidathion Oxon & $1 \mathrm{ppm}$ & $0,006 \mathrm{ppm}$ \\
Omethoate & $2 \mathrm{ppm}$ & $0,09 \mathrm{ppm}$ \\
\hline
\end{tabular}

In a previous work [13], we have used the same sol-gel method to immobilize electric eel acetylcholinesterase on screen printed electrodes (SPE), which led to development of an efficient amperometric biosensor able to detect the three target pesticides in olive oil. Thus, the sol-gel method has enabled us the preparation of two analytical devices based on two different detection modes: amperometric and optical. Both tools presented good operational stability, good storage stability and good reproducibility, but when applying on natural samples of olive oil, the amperometric biosensor give better results with recovery percentage of $100 \%$ of all the concentrations tested and it proved to be best suited for the determination of insecticides in real samples of olive oil. 


\section{Conclusions}

The immobilization of $28 \mathrm{mIU}$ of electric eel acetylcholinesterase, by sol-gel method, on microtiter plates led to the preparation of a simple, cheap, fast and efficient colorimetric test able to detect and quantify three of the most used pesticides in the treatment of olive trees (Malaoxon, Omethoate and Methidathion oxon), in a such complex matrix as olive oil. The measurement was performed without a laborious pre-treatment and after a simple liquid-liquid extraction. The developed Kits present a good operational and storage stability, a good reproducibility as well as a good analytical performance with limits of detection at least 10 times less than the maximum residue limit tolerated by the international regulations (MRLs).

\section{Acknowledgements}

Authors acknowledge with gratitude the Averroes programme (EC programme Erasmus Mundus) for granting this work.

\section{References}

[1] Garcia-Reyes, J. F., Ferrer, C, Gomez-Ramos, M. J., Molina-Diaz, A, Fernandez-Alba, A. R. Determination of pesticide residues in olive oil and olives. Trend. Anal. Chem., 26 (2007) 239-251.

[2] Luchetti, F. Importance and future of olive oil in the world market e an introduction to olive oil. Eur. J. Lipid Sci. Technol., 104 (2002) 559-563.

[3] Lentza-Rizos, C., \& Avramides, E. J. Pesticide residues in olive oil. Arch. Environ. Contam. Toxicol., 141, (1995), 111-134.

[4] Istamboulie, G., Andreescu, S., Marty, J. L., \& Noguer, T. Highly sensitive detection of organophosphorus insecticides using magnetic microbeads and genetically engineered acetylcholinesterase. Biosens. Bioelectron., 23 (2007) 506-512.
[5] Ellman, G.L., Courtney, K.D., Andres, V., Featherstone, R.M. A new and rapid colorimetric determination of acetylcholi-nesterase activity. Biochem. Pharmacol. 7 (1961) 88-92.

[6] Ebelmen, J. J. Sur les éthers siliciques. C.R. Acad. Sci., 19. (1844) 398-400.

[7] Andreescu, S., Barthelmebs, L., Marty, J-L. Anal. Immobilization of acetylcholinesterase on screen-printed electrodes: comparative study between three immobilization methods and applications to the detection of organophosphorus insecticides. Anal. Chim. Acta., 464 (2002) 171-180.

[8] Alvarez, G. S., Desimone, M. F., Diaz, L. E. Immobilization of bacteria in silica matrices using citric acid in the sol-gel process. Applied Microbiol. Biotechnol. 73 (2007) 1059-1064.

[9] Sassolas, A., Blum, L.-J., \& Leca-Bouvier, B.-D. Immobilization strategies to develop enzymatic biosensors. Biotechnol. Adv., 30 (2012) 489-511.

[10] Hayat, A., Barthelmebs, L., Marty, J.-L. A simple colorimet-ric enzymatic-assay for okadaic acid detection based on the immobilization of protein phosphatase $2 \mathrm{~A}$ in sol-gel. Appl. Biochem. Biotech. 166 (2012), 47-56.

[11] Bavcon Kralj, M., Treb se, P., \& Franko, M. Oxidation as a pre-step in determination of organophosphorus compounds by the AChE-TLS bioassay. Acta Chim. Slov., 53 (2006) 43-51.

[12] Ben Oujji, N., Bakas, I., Istamboulié, G., Ait-Ichou, I., Ait-Addi, E., Rouillon, R., Noguer, T. A Simple Colorimetric Enzymatic-Assay, based on immobilization of acetylcholi-nesterase by adsorption, for sensitive detection of organo-phosphorus insecticides in olive oil. Food Control. 46, 2014, 75-80.

[13] Ben Oujji, N., Bakas, I., Istamboulié, G., Ait-Ichou, I., Ait-Addi, E., Rouillon, R., Noguer, T. Sol-gel immobilization of acetylcholinesterase for the determination of orga-nophosphate pesticides in olive oil with biosensors. Food Control, 30 (2013) 657-661. 